\title{
(O que) pode a curadoria inventar?
}

\author{
Gabriel Menotti Gonring
}

Resumo: Observando marcas da consolidação da profissão de curador nas últimas décadas, bem como a disseminação de seu modo de atuação para além do campo tradicional da arte, esse artigo busca identificar as causas que nos levam a especular sobre a emergência de uma possível linguagem curatorial, que viria a se consolidar seja por reação às transformações internas do fazer artístico, seja por influência da lógica operacional das novas mídias. Abordando diversos aspectos das práticas curatoriais, o texto pretende apontar elementos que nos permitam refletir de maneira crítica sobre a autonomia simbólica do curador.

Palavras-chave: curadoria; autoria; desenho de exposição; redes de computador; linguagem.

Abstract: (What can) curatorial work create? - Considering the consolidation traces of the curator's profession in the last decades, as well as the dissemination of its modus operandi for beyond the traditional field of art, this paper aims to identify the causes that lead us to speculate about the emergence of a possible curatorial language, which would consolidate whether as a reaction to internal transformations of art making, or due the influence of new media's operational logic. By approaching different aspects of curatorial practices, this paper intends to outline some elements that allow to think critically about the curator's symbolic autonomy.

Keywords: curatorial work; authorship; exhibition design; computer networks; language.

Seria a curadoria uma forma de linguagem tão apta a produzir valor e sentido quanto outras modalidades de criação? Ou não passaria ela de um conjunto de procedimentos organizacionais neutros, responsável por estabelecer as bases para a circulação da arte e negociar sua existência em diferentes contextos?

O dilema é colocado de maneira explícita na sétima edição do Manifesta Journal. Lançado em 2009, o periódico curatorial inaugurava um novo ciclo destacando uma questão cada vez mais pertinente ao seu campo: a existência de uma certa gramática que articula os elementos em exposição. De antemão, é preciso alertar que se trata de 
um impasse falso. Ele parte da premissa de que a produção do sentido pode operar à parte dos processos que criam condições materiais, técnicas e legais para a sua expressão.

Como buscaremos demonstrar neste artigo, a curadoria se configura menos como modalidade artística do que como um conjunto de práticas por meio das quais a obra se realiza publicamente. Nesse sentido, trata-se de uma atividade particularmente ligada à dimensão de presença da linguagem, na qual o embate direto com o real é preponderante à atuação puramente simbólica.

Para entender esse modus operandi, é preciso destacar os princípios estruturadores de que a curadoria se serve. Eles aparecem mais claramente em práticas que apresentam diversas obras não como elementos isolados, mas por meio de relações entre si e com o público (AZIZOV et al., 2009, p. 5). Alguns dos principais exemplos de tais práticas podem ser encontrados no trabalho de Pontus Hultén e Harald Szeemann, duas personalidades que viriam a transformar o campo de ação da curadoria (OBRIST, 2008, p. 238).

Em 1977, o sueco Hultén foi o primeiro diretor do Centro Georges Pompidou, espaço pioneiro em abrigar exposições de arte em conjunto com outras formas de manifestação cultural - como debates, concertos e exibições de filmes. Szeemann, por sua vez, praticamente inventou o papel de curador independente ao abandonar seu cargo no Kunsthalle Bern, em 1969, passando a atuar como fazedor de exposições freelance.

Cada qual a seu modo, Hultén e Szeemann, expressam uma dilatação das possibilidades curatoriais em escopo e profundidade. Como colocado acima, o primeiro ampliou o conjunto de formas e linguagens acolhidas sob a égide institucional da arte; o segundo, o número de operações e espaços disponíveis para o curador. Graças a eles, a curadoria se tornou uma prática eminentemente multidisciplinar.

A atuação de Szeemann parece especialmente relevante se buscamos entender o alcance criativo das práticas curatoriais. Acumulando diversas funções, ele assumia uma postura de curador como artista que viria a se tornar cada vez mais central (senão explícita) no circuito da arte contemporânea. Recentemente, Groys (2007) sublinhou o fato de que o curador independente "faz tudo o que o artista contemporâneo faz": "viaja ao redor do mundo e organiza exposições que são comparáveis a instalações artísticas, porque são resultado de projetos, decisões e ações curatoriais individuais" (GROYS, 2007, p. 52).

Com a sedimentação de tais ações individuais, o que entra em questão é até que ponto o trabalho do curador não estaria interferindo nos princípios estruturadores das próprias obras. Por um lado, a intervenção curatorial parece necessária para assegurar a manifestação de uma produção artística cada vez mais conceitual, efêmera e/ou interativa (MARTIN, 2007, p. 36), seja criando condições estruturais para a sua realização, seja provendo mecanismos de decodificação que possibilitem o engajamento de públicos diversos.

Aracy Amaral também destaca a relevância do curador na articulação dos grandes eventos em torno dos quais gira o circuito de arte contemporânea, como documentas e Bienais, que ela chama de "exposições de curadores, e não mais de artistas" 
(AMARAL, 1988). Entretanto, o que Amaral vê nesse fato é outro sintoma da mesma lógica capitalista que fomenta tais exposições blockbuster, voltadas ao lucro e ao entretenimento.

Nesse contexto comercial, o curador aparece quase como um agente de marketing, responsável por empacotar de maneira sedutora uma produção essencialmente vazia e promover o artista como grife. Assim, sua atuação seria de fato criadora de valor e sentido, mas de maneira sobretudo publicitária.

Paradoxalmente, mesmo nos projetos que questionam essas grandes exposições, o que se faz sentir mais fortemente é a mão do curador. Podemos considerar, por exemplo, a $12^{\mathrm{a}}$ e mais recente edição da quinquenal documenta de Kassel (2007), em que se propôs uma reflexão histórica sobre a identidade do evento.

Para tanto, o diretor artístico Roger Buergel voltou-se para o surgimento da exposição e suas circunstâncias, em 1955, de modo a desenvolver uma "documenta das documentas" que trespassasse três tópicos curatoriais: modernidade, vida nua e educação. A inegável carga autoral desse projeto fez com que a crítica Lisette Lagnado chegasse a se referir a ele como uma obra de Buergel (LAGNADO, 2007).

No contexto brasileiro, encontramos outro caso relevante na proposta do curador Ivo Mesquita para a $28^{a}$ Bienal de São Paulo, realizada em 2008. Mesquita também buscou colocar essa instituição em xeque, e de uma forma ainda mais polêmica do que a encontrada por Buergel. Seu projeto Em Vivo Contato propôs que não houvesse obras físicas no pavilhão da Bienal, substituindo a exposição por um ciclo de seminários de 40 dias (uma quarentena), uma praça para apresentações e uma biblioteca/arquivo disponível à consulta pública. Dessa maneira, a apresentação de artistas seria substituída por uma reflexão sobre o próprio formato de exposição inspirado na Bienal de Veneza um modelo que, segundo Mesquita, já teria caducado ${ }^{1}$. Alvo de protestos, o projeto ganhou o apelido de Bienal do Vazio e não foi levado às últimas consequências. No fim das contas, apenas um andar do pavilhão ficou efetivamente desocupado.

A Bienal seguinte (2010), curada por Moacir dos Anjos e Agnaldo Farias, retomaria moldes convencionais para tratar de uma temática não menos ortodoxa: a relação entre arte e política. O teor experimental do evento teria ficado por conta do espalhamento de sua programação por lugares além do tradicional espaço expositivo, bem como a criação de terreiros. Esses terreiros eram construções circunscritas pelo pavilhão da Bienal, sendo cinco localizadas no seu interior e uma do lado de fora, próximo à entrada. Projetadas de acordo com diferentes configurações espaciais, seu principal objetivo era criar na exposição brechas para outras dinâmicas de uso e convívio - como a leitura, a apresentação de projeções e performances, e até mesmo o descanso do público.

Com isso, buscava-se tanto impingir certos ritmos ao percurso dos visitantes quanto dar lugar a obras que não se adequassem às normas arquitetônicas de uma galeria.

1 "Não há tempo para Bienal tradicional", in Folha de São Paulo, 10 de Novembro de 2008. Disponível em: $<$ http://www1.folha.uol.com.br/fsp/ilustrad/fq1011200732.htm> 
Por menos radical que essas intervenções possam parecer, é interessante ressaltar como elas envolvem o trabalho de outros agentes, representando uma abertura da prática curatorial à colaboração. Afinal, nem a programação, nem a estrutura dos terreiros eram definidas diretamente pelos curadores-chefe da Bienal: isso se dava por meio de uma equipe curatorial adjunta e de certos artistas convidados, como o carioca Ernesto Neto e o grupo holandês UNStudio.

Ao evocar esses exemplos, procuro ressaltar que a ampliação da agência da curadoria, que a promove como um modo de produzir valor e sentido, não está diretamente atrelada a um certo regime de exploração capitalista do fazer artístico. A proposta da documenta XII demonstra que as práticas curatoriais também podem servir para repensar o próprio sistema em que estão inseridas. Não obstante, isso não significa que o curador tenha assumido plenos poderes sobre o caráter da arte contemporânea. Como aconteceu no caso da Bienal do Vazio, essa figura ainda enfrenta obstáculos que delimitam sua atuação e com os quais precisa negociar. Na melhor das hipóteses, seu trabalho parece se dar em diálogo com os diversos atores envolvidos no processo expositivo.

Para compreender exatamente o que está em jogo na redefinição das práticas curatoriais, podemos começar virando a questão do avesso. À primeira vista, a impressão que se tem é que, desde o final da década de 1960, o curador está progressivamente invadindo o espaço do artista e usurpando suas prerrogativas autorais. Nesse sentido, o problema em legitimar a capacidade de invenção do curador estaria ligado à violência que isso representaria contra a autonomia de produção da própria arte.

Encharcadas de poder simbólico, as práticas curatoriais deixariam de ser operações intermediárias, passando a se interpor entre o público e o trabalho artístico. O curador, acumulando as funções de autor e autoridade, ficaria livre para mobilizar as obras como elementos na composição de um discurso pessoal e recolher os louros do processo (AZIZOV et al., 2009, p. 5). Aqui, podemos evocar a crítica feita pelo artista Daniel Buren à documenta V (1972), dirigida por Harald Szeemann: "é como se os trabalhos em exposição tivessem sido reduzidos a meras pinceladas na "enorme pintura" planejada pelo curador" (apud OBRIST, 2008, p. 90)

Entretanto, é preciso ressaltar outro rompimento das fronteiras entre arte e curadoria, revelado mediante um olhar mais atento sobre os terreiros da $29^{a}$ Bienal de São Paulo. Estou me referindo a uma forma de produção artística que se aproxima, de certa maneira, do desenho de exposição. Como veremos adiante, essa não é uma tendência recente, podendo ser retraçada desde as experiências realizadas pelas vanguardas modernistas entre as décadas de 1920 e 1940, e que posteriormente viriam a resultar no estabelecimento da instalação como um formato específico de produção artística (STANISZEWSKI, 1998, p. 3).

Muitos anos antes que o curador Szeemann assumisse uma independência criativa, foi o artista Marcel Duchamp que veio a empregar expedientes curatoriais para produzir 
uma obra. Com sua controversa Fonte (1917), ele teria elevado o mero procedimento de eleger um objeto ao status de gesto criador. Mais tarde, Kosuth destacaria a revolução que a empreitada de Duchamp causou para o fazer artístico, transformando a identidade da obra de arte "de uma questão de morfologia para uma questão de função" (KOSUTH, 1996). Não seria esperado que ela provocasse também algum efeito colateral, ainda que retardado, no campo da curadoria?

Sob essa perspectiva, a ampliação da autonomia simbólica do curador a partir do final da década de 1960 não estaria representando uma simples invasão do lugar do artista contemporâneo, mas uma completa renegociação das capacidades atribuídas a cada um desses papéis. Em outras palavras, não se trata da absorção de um campo pelo outro, mas de sua contaminação bilateral - uma contaminação que aparentemente começou no início do século passado, antes mesmo que esses campos estivessem plenamente definidos.

\section{A profissionalização e proliferação do curador}

Refletindo sobre as transformações a longo prazo do fazer artístico, obtemos uma compreensão mais profunda a respeito de como a autonomia criativa das práticas curatoriais pode ter se consolidado. Longe de ter sido requisitada pelo curador, ela parece ter emergido em reação ao surgimento de novas formas e teorias estéticas, num percurso que parece ter começado com os readymades de Duchamp e culminaria no final da década de 1960 - não por acaso, em meio ao que Lippard chamou da desmaterialização do objeto de arte, causada pelas práticas de arte conceitual (LIPPARD, 1997).

De modo a examinar mais minuciosamente esse processo de dupla metamorfose, é preciso em primeiro lugar entender a conjuntura que o torna possível. Para tanto, parece necessário introduzir outra dimensão do problema da curadoria nos dias de hoje, que não parece ser explicada somente pelas transformações internas do campo das artes. Trata-se da proeminência obtida pelo papel de curador não apenas em galerias e museus, mas também nas mais diversas áreas da vida quotidiana.

Steven Rand, fundador de uma organização comprometida em fomentar o trabalho de curadores emergentes, detecta um crescente interesse no estudo da área (RAND; KOURIS, 2007 , p. 8). De certa forma, a multiplicação de plataformas voltadas para a reflexão crítica sobre curadoria pode ser vista como um indício de seu amadurecimento como profissão, que se constitui por um corpo de saberes e técnicas relativamente definidos e já ocupa um lugar específico na sociedade. Parte dessas plataformas segue modelos acadêmicos tradicionais, como publicações - a exemplo do próprio Manifesta Journal, iniciado em 2003 pela fundação europeia Manifesta -, grupos de estudo e cursos de especialização.

Ao mesmo tempo, uma parte considerável dos programas voltados para a formação do curador adota um formato sem precedentes, muito mais dinâmico. Esses programas funcionam de maneira laboratorial, reunindo participantes de vários lugares do mundo 
em minicursos intensivos ou residências conjuntas. Eles são normalmente organizados por instituições independentes, muitas das quais baseadas nos principais centros globais de produção artística.

Além da transmissão de conhecimentos práticos e teóricos particulares da profissão, tais programas parecem estar voltados para o fomento do trabalho de curadores emergentes e a criação de redes de contato entre os participantes e desses com a produção e os acervos locais. Muito embora pareça desestruturado, esse modelo serve perfeitamente à atuação globe-trotter do curador contemporâneo e à formação multidisciplinar de que ele necessita.

No entanto, ainda mais sintomática do que essa cristalização do métier curatorial, é a popularização que parece acontecer no seu lastro. Tal popularização não implica um crescimento do contingente de curadores de fim de semana, mas sim a expansão de uso do termo para além do mundo da arte. Em 2006, ainda podia causar alguma estranheza o fato (amplamente alardeado pela mídia) de que um certo festival brasileiro de música popular tinha um curador. Em 2009, um artigo do New York Times nos leva a crer que esse havia se tornado o vocabulário corrente, tanto nessa quanto em outras áreas mais populares.

O texto do jornal nova-iorquino declarava, já em sua manchete, que o verbo curar não mais pertencia à turma do museu. Havíamos chegado a um ponto em que curadoria poderia servir para nomear atividades tão diversas quanto a seleção de mercadorias de uma loja de roupas, a definição da programação de uma casa noturna e a preparação do menu de uma barraquinha de comidas (WILLIAMS, 2009).

Nesse contexto, o que parece identificar as práticas curatoriais não é a sua concentração em um tema ou em um campo específico, mas sim, o seu grau de especialização. O curador seria um profissional do bom gosto, capaz de selecionar os melhores produtos e apresentá-los do jeito ideal. Desse modo, o termo é usado como uma marca de distinção - um modo inocente de agregar capital cultural a várias formas de comércio (WILLIAMS, 2009).

Embora não questione a validade desse emprego publicitário da palavra, também não creio que ele resuma completamente a importância obtida pelas práticas curatoriais nos dias de hoje. Há um componente que parece ainda mais relevante para a expansão dessas práticas além do domínio da arte, para o qual Obrist chama a atenção: a crescente necessidade de "selecionar, editar e definir múltiplos caminhos" em meio à caudalosa quantidade de dados em que nos encontramos imersos (apud BONOMI, 2011).

Obrist admite não apenas a proliferação da curadoria, como também a sua complexificação no registro popular, onde o termo teria evoluído a partir de uma analogia estabelecida nos anos 1990 entre o curador e o DJ. Evocando o escritor JG Ballard, ele diz que vê nas práticas curatoriais uma forma de criar junções. Nesse sentido, mais do que o trabalho quase editorial em cima do material produzido por outras pessoas, a curadoria implicaria o estabelecimento de diálogos (uma visão que Obrist parece exercitar 
literalmente, por meio de sua prolífica carreira de entrevistador). A criação de tais interações seria necessária para transformar em conhecimento a crescente produção de informações na era digital (apud BONOMI, 2011).

Seguindo a pista de Obrist sobre as causas da popularização da curadoria no século XXI, é possível delinear um outro motivo para a sua legitimidade como forma de linguagem ou prática criativa. Além das transformações internas do fazer artístico, que passariam a requisitar uma intervenção contundente do curador, a relevância dessa figura também parece estar relacionada a uma mudança mais geral nos modos discursivos e nas formas de organização da sociedade. Colocando de outra maneira, podemos dizer que a curadoria ganha autonomia por se adequar a um regime de atuação sistêmica que se torna cada vez mais importante na contemporaneidade por conta das chamadas novas mídias.

\section{Indexação de conteúdos e a criação em novas mídias}

Por novas mídias, não me refiro apenas aos meios de comunicação ou representação inteiramente baseados no desenvolvimento da computação digital e das redes telemáticas, mas sim a todos aqueles que adotem essas tecnologias, reajam a elas ou com elas interajam.

Atenta aos efeitos desses meios nas práticas curatoriais, Krysa sublinha a sua relação com um regime de produção imaterial que caracteriza as sociedades em rede, pós-fordistas (KRYSA, 2006, p.9). Para ela, as redes de computadores transformam a curadoria tanto ao expandir seu campo de produção - que passa a incluir "o espaço da Internet" -, quanto por estender seu foco de atenção "do objeto aos processos aos sistemas em rede dinâmicos" (KRYSA, 2006, p.7).

Para dar conta desses desdobramentos, Krysa evoca a ideia de sistema, que toma de empréstimo da teoria cultural de Edgar e Sedgwick, e define como "uma coleção de partes inter-relacionadas, que simultaneamente mantém a sua ordem interna e extrai os recursos necessários para a sua sobrevivência e reprodução a partir de um ambiente externo" (KRYSA, 2006, p.14). Sensível aos princípios operacionais das novas mídias, uma perspectiva sistêmica seria capaz de elucidar o modo como essas tecnologias afetam os arranjos expositivos produzidos pelo fazer curatorial, bem como a constituição das obras que the servem de matéria-prima e os processos de que se utiliza nos dias de hoje (KRYSA, 2006, p.14).

Uma literal intersecção entre sistemas de informação e práticas curatoriais pode ser percebida já nas atividades voltadas para a organização de conteúdos online. São ações aparentemente ordinárias como o bookmarking (a indexação pública ou privada de links) e o link forwarding (o compartilhamento de websites com os seus contatos na rede) que possibilitam manejar coletivamente a complexidade informacional da Internet.

Esse tipo de ação tem se cristalizado não apenas em plataformas próprias, como sites de social bookmarking e tumblelogs, mas também no cerne das redes sociais. O Facebook, 
por exemplo, possui funções que permitem aos seus usuários curtirem páginas (dentro e fora do site) e compartilharem as postagens uns dos outros. A partir de 2011, o Google buscou implementar um esquema semelhante com o indefectível +1 - um botão que pode ser usado para sugerir certos resultados de busca aos seus contatos que possuem conta no site, aumentando a relevância desses links.

A indexação de conteúdos na internet pode ser entendida de duas formas: em primeiro lugar, como uma organização coletiva da própria topografia da rede; em segundo, como uma democratização das possibilidades de curadoria, que encontra na rede espaço para prosperar. Nesse sentido, essas atividades e plataformas de filtragem representariam algo como o push-button publishing que se estabeleceu com os blogs como alternativa às dinâmicas de informação tradicionais dos meios de comunicação de massa.

Para Kasprzak essas plataformas de filtragem também renegociam o significado das práticas curatoriais (KASPRZAK, 2008). Por um lado, a sua abertura à participação popular permite a emergência de uma aleatoriedade inesperadamente benéfica, que ajuda a escapar do consenso raso e da ortodoxia canônica. Ao mesmo tempo, o ritmo intenso em que elas operam solapa o contexto e os propósitos do próprio ato de indexar informações. Em outras palavras, essas plataformas promovem curadoria como uma acumulação de referências efervescentes, altamente pessoal, porém descuidada.

Mas isso não significa necessariamente que as exigências conceituais do mundo da arte estejam em conflito com a dinâmica organizacional das redes telemáticas. Pelo contrário, esta pode muito bem servir para revitalizar aquelas, oxigenando perspectivas institucionais.

Um exemplo de contaminação propositiva entre a tradição curatorial e as novas mídias parte dos surfing clubs, blogs de artista que surgiram por volta de 2002-2003 buscando se apropriar da Internet como um "mercado de pulgas de imagens e discursos" (RAMOCKI, 2008). Os grupos por trás desses sites os utilizavam para disseminar não apenas trabalhos de arte (tanto próprios quanto alheios), mas também elementos particulares da estética da rede, como banners e GIFs animados, misturando indiscriminadamente uma coisa à outra.

O que caracterizava os surfing clubs como formato era menos o seu conteúdo do que a sua modalidade discursiva, fundamentada no caráter subjetivo, informal e aberto dos comentários dos posts de blog. Do modo como é colocado pelo artista Marcin Ramocki, o post aparece como uma prática criativa a meio caminho entre a pesquisa curatorial e o gesto de arte conceitual. Baseando-se nele, os surfing clubs assumiam dimensões duchampianas de um jogo semiótico entre os participantes e a audiência que "em alguns casos são sinônimos" (RAMOCKI, 2008).

Como o próprio nome indica, esses sites estavam intimamente ligados à prática de surfar na rede, se alimentado da (e retroalimentando a) deriva do público pela internet. Quando as possibilidades de se perder no ciberespaço se diluíram, graças à estruturação da dita Web 2.0, os surfing clubs acabaram por se enquadrar nas plataformas de social bookmarking supracitadas. De todo modo, seu espírito de desbravador ainda pode ser 
reconhecido em art blogs como Today and Tomorrow e VVORK. O time de responsáveis desse último, inclusive, já até organizou exposições em espaços de arte contemporânea como a Galerie West (em Haia, 2007) ${ }^{2}$ e o MU (em Eindhoven, 2009). ${ }^{3}$

De acordo com a perspectiva proposta por Krysa, isso não parece inesperado. A pesquisadora defende que o desenvolvimento da curadoria online precisa ser entendido em paralelo às tentativas institucionais de "responder à emergência da Internet e incorporá-la como parte de seu território" (KRYSA, 2006, p. 16). Nesse sentido, Dietz aponta como os museus tradicionais vinham reagindo à explosão da internet ao reorganizarem a acessibilidade do seu acervo e requalificarem o papel do curador (DIETZ, 1998). Os tours online e as exposições ampliadas ou estendidas por meio da rede seriam os sintomas mais óbvios dessa reação. Se por um lado tais estratégias corroboram com a diluição da exclusividade do espaço (físico) da galeria, por outro, elas promovem a presença dos museus por uma ecologia midiática onde, a princípio, essas instituições não teriam qualquer primazia.

Para Dietz, a cultura da interface contribui com a tendência pós-moderna de derrubar autoridades oniscientes e acabar com as suas prerrogativas de gatekeeping (DIETZ, 1998). O contexto das redes nos permite enquadrar o curador no papel de um filtro de informação (filter feeder) cujos principais privilégios sobre outros possíveis gatekeepers (como membros do público ou determinados softwares) parecem ser meramente institucionais.

Paul parte dessa premissa para colocar em questão "as políticas de seleção e o grau de agência" de diferentes atores no processo curatorial (PAUL, 2006, p. 86). Ela ressalta que, em um regime de novas mídias em que a produção cultural se mostra cada fez mais conectada, mesmo a exposição mais convencional "não está atrelada apenas ao contexto de uma única instituição, mas sim, existe por meio de uma rede em que o controle curatorial tende a ser distribuído" (PAUL, 2006, p. 92). Levando em consideração as implicações socioeconômicas apontadas por Krysa, podemos presumir que façam parte dessa rede não apenas os supracitados softwares e membros do público, como também tecnocratas e patrocinadores, cuja influência sobre o arranjo expositivo passaria a se tornar ainda mais direta.

Operando em meio a essa pluralidade, o curador de arte contemporânea seria levado a abraçar a transformação que lhe é imposta pelas novas mídias. Algumas das possíveis novidades na atuação desse profissional são enumeradas por Schleiner, incluindo a atuação em espaços periféricos em oposição à galeria e ao museu; a expertise em cultura pop e história da tecnologia em oposição à história da arte; a interação com outros filtros e artistas em oposição ao vínculo com ricos mecenas; a concentração em localidades secundárias em oposição às metrópoles; a aversão às instituições em oposição à intimidade com a burocracia; a atenção aos objetos efêmeros e obras difíceis de preservar em oposição

2 Disponível em: <http://rhizome.org/editorial/2007/oct/1/galerie-west-vvork-exhibition/>. Acesso em: 03 Mar 2015.

3 Disponível em: <http://www.vvork.com/?page_id=13441>. Acesso em 03 Mar 2015. 
à arte comodificada; e a penetração em comunidades alternativas em oposição ao isolamento em meio à comunidade artística) (PAUL, 2006, p. 92).

Nessa série de mudanças, começamos a perceber como o intercâmbio das redes de computador com as tradições da arte contemporânea pode promover uma forma mais pessoal e dinâmica de curadoria. É, no entanto, improvável que sejam os próprios curadores a empregar novas mídias para minar a ortodoxia de sua profissão. Para Krysa, pelo contrário, essa influência fatal seria causada por artistas "engajados com a abertura das estruturas tecnológicas" (KRYSA, 2006, p. 20). De modo a explorar essa hipótese, chamo a atenção para características das novas mídias que trazem a criação artística para ainda mais perto das práticas curatoriais, aumentando a interpenetração entre ambas para além do campo informático.

Em primeiro lugar, é preciso destacar que as operações que Manovich indica como fundamentais para a produção em novas mídias são as mesmas que estão na base de qualquer curadoria: a seleção de elementos a partir de um acervo de dados e a sua composição em um conjunto (MANOVICH, 2001, p. 118). Além disso, ele também aponta para o fato de que o computador transforma em regra um modo bem específico de representação: a visualização de dados (MANOVICH, 2002). Seguindo tais parâmetros, diversos trabalhos nessa área poderiam bem ser considerados como uma forma pré-planejada de exposição.

Para entender melhor o que isso significa, podemos levar em conta o funcionamento do screensaver Electric Sheep, feito por Scott Draves. Esse trabalho consiste numa animação de fractais multicoloridos, gerada em tempo real por computação distribuída. À primeira vista, podemos ser levados a pensar que tais imagens constituem superfícies inteiras e autoevidentes, possuindo a mesma integridade de uma pintura. Essa impressão é reforçada pela forma autônoma com que a obra pode ser exibida e negociada. Uma versão específica do screensaver, por exemplo, foi comprada pelo Google e se encontra adornando o saguão do campus corporativo da empresa, pendurada na parede como um quadro de autor famoso (GILBERTSON, 2006).

No entanto, o que está de fato sendo mostrado em Electric Sheep é o processo evolutivo de uma população de robôs-software (as "ovelhas"). A cada vez que executa o programa, o computador se comunica pela internet com todos os outros em que ele está rodando. Conjuntamente, essas máquinas calculam complexas imagens que jamais se repetem. Nesse sentido, as formas aparentemente fechadas que a obra apresenta são na verdade uma expressão da interação dinâmica entre elementos discretos de dois níveis: os computadores em rede e os robôs-software.

Na medida em que o screensaver é uma apresentação desse sistema, o trabalho do artista consiste em definir parâmetros para que os diferentes elementos sejam exibidos conjuntamente. Portanto, ainda que o resultado visual de Electric Sheep se assemelhe 
a uma tela abstrata, poderíamos argumentar que as operações envolvidas em seu processo de criação estejam mais próximas do ato de organizar um arranjo expositivo do que de pintar um retrato.

Quando o fazer artístico passa a se utilizar desses expedientes de seleção e composição, parece quase natural que ele acabe se desdobrando também em práticas curatoriais propriamente ditas. Nesse caso, um exemplo vem da dupla australiana Soda_Jerk, autores do primeiro longa-metragem narrativo produzido inteiramente a partir de material sampleado (Pixel Pirate II: The Attack of the Astro Elvis Video Clone, 2006). Seus integrantes realizam regularmente exposições e mostras de vídeo. Para eles, a curadoria é "como uma extensão da prática artística do remix. Assim como a edição de uma mixtape, curadoria envolve agrupar trabalhos distintos e forjar novas relações entre eles" (SODA_JERK, 2006).

Em um ambiente em que as formas de produzir e de consumir conteúdos se aproximam, as mídias baseadas em computação digital fazem com que os papéis da audiência, do artista e do curador se tornem cada vez mais intercambiáveis. Trabalhos como os de Scott Draves e do Soda_Jerk exemplificam como essas tecnologias promovem modalidades de criação que se utilizam de operações básicas da curadoria, podendo recontextualizar significativamente essa prática. Assim, enquanto por um lado a profissão de curador ganha vulto e se estrutura com cursos e publicações, por outro, as técnicas que ela emprega parecem se tornar cada vez mais disseminadas - até banais.

\section{Considerações finais}

Até aqui, foi enumerada uma série de fatores que podem levar à crescente autonomia das práticas curatoriais, seja por reação às transformações internas do fazer artístico, seja por influência da lógica operacional das novas mídias. O caráter da curadoria como processo autoral precisa ser compreendido diante dessa multiplicidade de pretextos: simultaneamente em relação à emergência de novas formas de criação e ao reposicionamento da função do curador nos dias de hoje.

Na esperança de contemplar ambos os lados da questão, pretendo concluir retomando a ideia de rede, para além da sua acepção tecnológica corrente enquanto sistema distribuído de computadores hiperconectados. Aplicado como um modelo heurístico, esse conceito nos permite obter um enfoque relacional sobre o trabalho artístico. Quando entendemos a obra - seja ela instalação, pintura, filme, performance ou qualquer outra coisa - como uma rede, assumimos que ela não estaria contida em nenhum objeto ou processo singular, nem dependeria unicamente do gesto criador do artista, mas existiria sempre em desenvolvimento, distribuída por circuito não-hierárquico que envolve outros atores, objetos e processos. 
Proponho que as práticas curatoriais desempenhem uma função de mediação preponderante na topografia desse circuito, uma vez que criam as condições de publicidade que tornam o trabalho artístico apreensível. Por meio da articulação de elementos diversos, elas constroem como coerência aquilo que se abstrai do processo de criação. No desenho da exposição que se estabelece, o valor e o sentido do trabalho se atualizam.

Encontramos aqui uma medida de como a intervenção do curador pode contribuir para a produção da obra e para a consolidação de determinadas abordagens poéticas. Ao mesmo tempo, esbarramos em uma condição que nos leva a questionar a sua autonomia simbólica. Nessas circunstâncias, não parece possível defender a curadoria como uma forma de expressão em pleno direito. A atuação como articulador de redes circunscreve a capacidade discursiva das práticas curatoriais à disponibilidade não apenas de rastros do processo de criação, mas também dos artifícios necessários para capturar e mobilizar tais rastros como resultados do fazer artístico.

Nesse sentido, é falso o dilema colocado inicialmente, que nos levava a categorizar as práticas curatoriais ou como uma forma de linguagem ou como um conjunto de procedimentos organizacionais. Se as práticas curatoriais são de fato linguagem, elas não se realizam senão por meio de procedimentos organizacionais.

Gabriel Menotti Gonring atua como crítico e curador. É professor de Edição e Multimídia na Universidade Federal do Espírito Santo. Possui um doutorado em Media and Communications por Goldsmiths (Universidade de Londres) e outro em Comunicação e Semiótica pela PUCSP. É autor de Através da Sala Escura: Espaços de Exibição Cinematográfica e VJing (Intermeios, 2012) e co-editor de Besides the Screen: Moving Images Through Distribution, Promotion and Curation (Palgrave, 2015).

gabriel.menotti@gmail.com

\section{Referências}

AMARAL, A. O curador como estrela, 1988. Disponível em: <http://goo.gl/kT4Ba>. Acesso em: 4 mar. 2012.

AZIZOV, Z; BISHOP, C; FIJEN, H; MANACORDA, F; RAMOS, F. Manifesta journal, Itália, v. 7, 2009.

BONOMI, B. B. The Art of Curation. Huffington post, 27 out. 2011. Disponível em: <http://goo. $\mathrm{gl} / 1 \mathrm{lq} J \mathrm{H}>$. Acesso em: 4 mar. 2012.

DIETZ, S. Curating (on) the web, 1998. Disponível em: <http://goo.gl/rgXOe>. Acesso em: 4 mar. 2012. 
FIORATTI, G. Não há tempo para Bienal tradicional. Folha de São Paulo, 10 nov. 2008. Disponível em: <http://www1.folha.uol.com.br/fsp/ilustrad/fq1011200732.htm>

GILBERTSON, S. Electric Sheep Invade Google. Webmonkey, 20 dez. 2006. Disponível em: <http:// goo.gl/scn7W>. Acesso em: 4 mar 2012.

GROYS, B. The Curator as Iconoclast. In: RAND, S; KOURIS, H (eds.). Cautionary tales: critical curating. Nova York: Apexart, 2007, p. 46-55.

KASPRZAK, M. For What and For Whom? Vague terrain: curediting, outono, 2008. Disponível em: $<$ http://goo.gl/XnDBO>. Acesso em: 4 mar. 2012.

KOSUTH, J. Art After Philosophy. In: STILES, K; SELZ, P. (eds.). Theories and documents of contemporary art. Los Angeles: University of California, 1996, p. 841-846.

KRYSA, J. Curating immateriality: The Work of the Curator in the Age of Network Systems. Reino Unido: Autonomedia, 2006.

LAGNADO, L. Como ser moderno, hoje. Trópico, 2007. Disponível em: <http://goo.gl/c90t8>. Acesso em: 4 mar. 2012.

LIPPARD, L. Six years: the dematerialization of the art object from 1966 to 1972 . California: University of California, 1997.

MANOVICH, L. The language of new media. Cambridge: MIT, 2001

Data visualisation as new abstraction and anti-sublime, 2002. Disponível em: $<$ http://goo. gl/9p623>. Acesso em: 4 mar. 2012.

MARTIN, J-H. Independent Curatorship. In: RAND, S; KOURIS, H (eds.). Cautionary tales. Nova York: Apexart, 2007, p. 36-45.

OBRIST, H. U. A brief history of curating. Zurique: JRP/Ringier, 2008.

PAUL, C. Flexible contents, democratic filtering and computer-aided curating: models for online curatorial practice. In: KRYSA, J. (ed.). Curating immateriality. Reino Unido: Autonomedia, 2006, p. 85-105.

RAMOCKI, M. Surfing clubs: organized notes and comments. 27 maio 2008. Disponível em: <http:// goo.gl/i4Y94> Acesso em 4 mar. 2012.

RAND, S.; KOURIS, H. (eds.). Cautionary tales. Nova York: Apexart, 2007.

SODA_JERK. Curating, 2006. Disponível em: <http://www.sodajerk.com.au/sj/curate.html>. Acesso em: 29 set. 2009 (Atualmente fora do ar).

STANISZEWSKI, M. A. The power of display: A History of Exhibition Installations at the Museum of Modern Art. Cambridge: MIT Press, 1998.

WILLIAMS, A. On the Tip of Creative Tongues. The New York Times, 2 out. 2009. Disponível em: $<$ http://goo.gl/nYqbX>. Acesso em: 4 mar. 2012. 